\title{
Implying an International Strategic Recruitment and Its Impact on Local Workers
}

\author{
Nashwan Ahmed Sharhan, Rashad Yazdanifard \\ Centre of Post Graduates Studies, Limkokwing University of Creative Technology, Cyberjaya, Malaysia \\ Email: nashwan25@gmail.com, rashadyazdanifard@yahoo.com
}

Received 9 February 2014; revised 9 March 2014; accepted 16 March 2014

Copyright (C) 2014 by authors and Scientific Research Publishing Inc.

This work is licensed under the Creative Commons Attribution International License (CC BY). http://creativecommons.org/licenses/by/4.0/

(c) (i) Open Access

\begin{abstract}
The close relationship among economic change, recruitment strategies and its impact on local workers whether they are highly skilled or not is showed and explained in this article. Population aging, the rising demand for talent in emerging economies and increasing cross-border employment opportunities is what drives global demand for highly skilled workers which are all intensifying the competition for talent. The variety of policies and practices reflecting corporation's goals in the absence of an international consensus on global policy frameworks and national governments and values is discussed in this chapter. The supply and demand factors converge in the selection of foreign skills which is the trend in national recruitment strategies and shows clearly in the direction of hybrid arrangements and values migrants' long-term contributions to the receiving country through the supply-driven point's system values. The abilitiesy of migrants to fill labor shortages are emphasized by demand driven systems to fill labor shortages.
\end{abstract}

\section{Keywords}

Workforce Behavior; Globalized Management; Cultural Diversity; Pressure

\section{Introduction}

There is a need to compete globally and expand the paths and possibilities abroad and in a globalized level in order to compete, increase productivity, and maximize the organization or company profit. It's also important to ensure a solid and strong management level to compete with the globalized environment efficiently and effectively and integrate the workforce power. Recruiting an international workforce power becomes mandatory in order to maintain or lead in producing a product or serving a service as organizations grow and begin to compete 
in a global scale. The goal for an international scaled company or organization is to be on top and leading the industry to ensure maintaining the lead to achieve a competitive advantage in a global international scale [1]. Globalization has had it effect on management and leadership through market and customer base, as well as international employee transfer rates, competition, and an increase in opportunities. International recruitments play a role in benefiting the expanding organization and/or company knowledge experience and its competitiveness. However, it has some downsides such as the foreign worker can cause a jealousy among staff as he will be treated better or given a sense for the local workers that their jobs are unsecure and they may lose their lives as the foreign or international worker may change the way the workers have already adapted. Foreign workers' issues have received increase medium and national attention. However, up to date there has been limited research on the nature and consequences of employment of foreign workers in the global [2].

Companies usually considered their customer base and market to be origin of their country prior to the recent increase in globalization. Now because of the globalization management these companies can now consider the entire world as their market and available customer base. Management has been affected by globalization which has caused it to expand cross the globe and this allowed production to increase as "the most critical global attribute is open-mindedness" [2].

\section{Implying an International Strategic Recruitment and Its Impact on Local Workers}

Implying an international strategic recruitment and its process by manager's impacts on local workers and globalized management issues; managers will come across opportunities, problems, and challenges as they analyze each category. "If you have to be sensitive and responsive to national differences, you better not put someone who is an arrogant and ethnocentric person" [2].

Churchwell is making a valid point by mentioning that not any one can be a globalized or becomes an international manager. The manager or person in charge should have some characteristics that will allow him/her to either adapt the organization going globally or make the whole organization adapt to the outside environment. Daniel Altman has discussed this in the New York Times about "Managing Globalization: If it's here to stay, what do we do now", [3].

\subsection{The Impact on Ethics}

I-Requiting foreign construction or normal low level jobs such as workers in construction sites, cleaners in organizations or waiters in restaurants or hotels brings a lot of foreign workers that the local country workers either doesn't want because of their low level or sometimes the management itself refuses to recruit the local's for the sake of getting cheaper labor wages [4].

The impact from the ethical point of way may occur, managers are creating unemployment to the locals which will lead to the consequence of poverty and result into many problems in the country's economy and the worst possible scenario is high rates of inflation and high rates on unemployment. Another reason is recruitment injustice in which foreigners are getting the jobs no matter how skilled or hard working they are just because they are foreigners, while locals may have more experience than these foreigners which will lead to injustice and unethical act for example Malaysia has recruitment rate of 45,000 foreign workers from India to meet the demand in 13 small-scale business sectors, [5]. Malaysia should analyze their behavior and what they like and don't like before recruiting them.

II-Recruiting employees in operational level and secretary level. Some foreign workers are unable to merge with the local workers for a couple of reasons such as they are getting more wages than their local colleagues who are doing the same job. Also it is common that foreigners are getting well treated by superiors which can be categorized as un-ethical act. Usually the work performance is fundamental that employees are hired to perform in exchange for their compensation packages and this implies on foreigners [6].

III-Recruiting foreigners for top level management and CEO. It's common in some organization to recruit a foreigner CEO and many of them will have a preference to foreigners and has dictator management style and affect the recruiting process and can layoff the local workers easily in favor of the foreigner workers.

\subsection{The Impact in Cultural Differences}

Due to the complexity of global operations it requires managers to devote attention to matters such as cultural 
diversity and economic development [7]. Culture plays a big role in growing and reaching to a more opened organization. The factors in culture that impact the recruiting strategy are dressing, religious practices, customs, social values, family obligations and non-verbal behavior. Managers should study these factors and make sure they understand them in order to recruit properly and manage the right person for the right job. Employees' innovative behavior depends greatly on their interaction with others in the workplace [8].

For example, the dress for gender as some employees especially women in some cultures like to wear a scarf or hijab around their face all the time others prefer not. Another factor is religious practices some religions require time during working hours each and every day for prayer time or time off for special religious days. Customs is another factor in which some cultures can or can't have some kind of foods and drinks, or may have rules about how food is prepared [9].

But what managers should do to prevent this impact? The answer is simple managers can make use of staff cultural skills, promote cultural celebrations, be flexible and not to discriminate against workers because of their different cultural background through continuous awareness, training and acceptance of different cultures.

\subsection{Global Competitiveness}

Important decision needs to be taken in order to compete globally, and gain competitive advantage to support the organization or companies to achieve its goals. The way of recruiting employees at local and global level whether a normal worker, operational employee or even at the top level management has to improve. The impact for example could be on the top management as the company recruits a foreign well talented individual to run and lead the organization towards success who will be the image of the company. It will have a negative implication for example if an American company is run by a Japanese manager or vice versa which might trigger a thought that the organization is run by Japanese which in reality not. In the contrary, many conflicts and civil wars will lead to huge displacements and local workers will immigrate and take their knowledge and power elsewhere which is putting further pressure on the system and increasing reliance on foreign workers” [10].

Managers also should consider the cost of local workers and foreign workers "Since the construction industry requires massive manpower, labor supplies are always essential, and have become the most expensive resource deployed within the industry" [11].

\subsection{The Impact on Performance}

The company can increase its performance through local and foreign staff when they work together in a team work to achieve the goals needed. Staff can perform their best on the job under the best circumstances. They either can both preform very well or one will perform well and the other one less for many reasons from discrimination to injustice in work and so on. The availability of a management plan in advance, the decision making will affect the performance of the outcome [12].

In order to improve performance when we have mixed workers local and foreigners it is crucial to implement a self-managed work team which is an independent and self-ruled form of work which gives a group of workers the responsibility for regulating, organizing and controlling of their jobs and the conditions that are surrounding them [13].

\subsection{The Impact on Knowledge Gained}

This is the outcome of the whole recruitment process as these managers will know whether they did the right recruitment decision or not. Either way they will know based on the knowledge the local's gained from the foreigners or the knowledge the foreigners gained from the local's which can be measured by implying some tests to the employees. There is one test which is called situational judgment tests (SJT) which is commonly used as employee-selection and employee-screening tools and have been developed to predict employment success and the amount of knowledge the job requires [14].

\subsection{Transition to a More Globalized World Economy}

The challenge to the transition to a more globalized world economy is to keep it human and fair, which is to agree on values, rules and procedures which organizes and allows us to set up the necessary governance, [15]. In a speech of the director general of the World Trade Organization; "That is why organizations like the WTO, 
where international trade rules are agreed by consensus of all the members, must be improved and reinforced.” Another thing the economic growth of the country, in particular by alleviating labor shortages in selected sectors of the economy but they still bring a lot of disadvantages to the country in terms of employment opportunity for local workers. A foreign worker is a person who was employed in a country on a temporary basis to which the person is not a citizen. Foreign workers are recruited by a company, recruitment agency or hired whilst they were seeking a job in the country to supplement the workforce of the country for a limited term or to provide skills on a contractual basis that the country seeks [5].

There are many factors that influence the managers' decision when they start to implement the international recruiting strategy for both sending and receiving countries who are using a variety of regimes to regulate and harness the benefits of international recruitment [16]. It shows a trend toward hybrid regimes that combine both supply and demand factors that experiment with two step recruitment to ease the transition of temporary migrant's status to permanent status. While competition for international students and rising the recognition of the economic value is to be extracted from their displacements. This typology provides a useful context for the analysis of recruitment strategies. First, however, we examine the state of global competition for these skills [17].

\section{The Global Competition for Skills}

Competition for skills is arguably the main reason as diffusing technologies and knowledge as well as labor mobility can contribute to economic development the search for talent has become a major concern for Asian business leaders. In 2011, it ranked among the top 10challenges for CEOs in Asia [15] reflecting the changing business landscape and fluctuations in supply of talent, both within regions and globally. Many governments discovered the fact that immigration policies affect future economic prosperity. From these factors four shape this competition: changes in demographic structures with population aging, brain circulation, the knowledge-intensive economy, and growing demand for talent in emerging markets. Many countries have shifted and encouraged recruiting migrants to fill low skilled jobs or to recruit them on the basis of their family ties to attracting highly skilled workers independently of their race and country of origin [18]. In addition, research has shown that investment and highly skilled professionals are highly connected, where an increase or a change of direction in the flow of one necessarily impacts the other [19]. The growth and spread of multinational companies has also encouraged global labor mobility.

Chiquiar and Hanson had argued that countries with high return to skill and wage, as in much of the developing world, there will be the negative selection of immigration. Those with the greatest motivation to migrate to the US will be individuals with below-average skill levels in their home countries, as appears to be the case in western Europe, there will be positive selection of immigrants. Those with above-average skill levels will have greater incentive to migrate. Relative to earlier cohorts, recent immigrants earn lower wages than natives at time of arrival and take longer for their earnings to converge to native levels, [20].

\subsection{Demographic Change}

As fertility declines, life expectancies rise and populations age, an increasing number of countries face declining work forces and potential labor shortages. At the same time as the number of dependents (people over age 65 and under age 14) is rising. The demographic transition has economic and fiscal implications for emerging economies. Governments are aware of these challenges and are boosting efforts to attract scientists, engineers, other high-level management, and technical workers. Countries like Japan and South Korea which traditionally have not been open to foreign immigration face a lot of challenges [15].

\subsection{Brain Circulation}

Outward movements of the highly skilled used to be described as the "brain drain.” Recently this term has been replaced by the term "brain circulation". Migration is no longer a simple one-off event. Labor circulates globally. People no longer leave their home country permanently to take up residence in another; they study abroad, work in a different country, and many return to their home countries although some also reside in countries. Policy objectives are changing "from preventing the brain drain to making the most of the brain circulation" [21].

Not only do receiving countries benefit from specialized expatriate workers, but immigrants' skills, networks and knowledge generate important pay offs to their families in their home countries. Countries also benefit from 
the skills and experience acquired overseas due to the movement of personnel and skilled workers returning to their home counties [22]. The Reverse flows seem to be smaller than initial outward flows, countries can benefit from returning workers. For example, Chinese government has plans to encourage the return of the million or so who have studied abroad between 1978 and 2006; the number of returnees has increased sharply [23]. A recent survey reported that $23 \%$ of Chinese returnees decided to return to China due to various government incentives which they felt are more beneficial to them more than the hosting countries [23]. Fast growth, movement up the value chain and improved working conditions are an integral part of the attraction to recent graduates and experienced professionals [24].

\subsection{Demand from Emerging Markets}

Highly-skilled labor such as: Science, Technology, Engineer, and Mathematics workers are now the wheel of the global economy and critical to any emerging countries' economic growth. China and India are now seeking more skilled workers and intensifying global competitive pressures [25]. It is argued that the reverse brain drain of talented workers returning to their home countries has not been sufficient to the rising need for skilled workers in these economies implying growing shortages of highly-skilled labor innovation also includes [25]. Emerging markets needs to be executed very well. In order to execute an effective and safe way for a market to emerge, managers have to implementation new ideas. Here, managers well encourage innovative behavior as behavior directed towards the initiation and application (within a work role, group or organization) of new and useful ideas, processes, products or procedures [26].

\section{Discussions}

This paper discusses in depth about the impact on the recruitment process from various aspects. Managers are responsible for any acts they pursue towards achieving organizations goals such as the ethical acts towards workers and also the behavior and compensations that the top management should do to compensate and maintain the workers whether local or foreigners without making a diversification between the two of them. Human resource management department should run its one system of analyzing the important steps before selection employees wither local or international. The HRM department should first know what are the skills required to hire the right person at the right place.

Then whether there is a need to recruit from the local workforce or the foreign workforce. It's important when recruiting employees to analyze the potential cost that might be charged when recruiting local or international worker. The rate of wages might differ from nation to nation so careful analysis of the cost of recruitment is mandatory for managers to decide. Another important aspect is for example will there be enough workers who have enough power to perform the job on time or not. Will they live near the job place or not. If they are foreign instructors or assembly workers with lower wages than the local workfare wages, they will need a place to stay so the manager will have to come up with a solution for them and it will be definitely costly so managers might think cutting cost when bringing international labor with lower wages but will deal with other costs that might make the foreigners total cost more the local workforce because the local will have their home to stay. The knowledge and experience is another important point when implying a strategic recruitment process.

Managers should recruit the worker with enough knowledge and experience for the job so managers should be very selective because they don't want someone who is highly skilled employee for a job that doesn't really need that amount of knowledge this will result in misappropriate placement for the job. The highly skilled employee will be costly for nothing while a lower skilled employee will perform better than the highly skilled one because the highly skilled got higher potential to work in more complicated projects rather than simple one which can be performed by normal skilled workers. Managers don't need to recruit highly skilled employees by wasting money on highly skilled employees. On the other hand, hiring non skilled employee's for a job that requires a certain amount of skills will lead to many effects. One effect is for the company for example lower employees might have more knowledge and experience than the leader who lacks a lot of managerial skills. This will lead employees to preform less efficiently. It's also important for managers to recruit the right people for the right job without forcing them to do things against their will, power, or knowledge.

\section{Conclusion}

The importance of analyzing and discussing the process of implying an international strategic recruitment and its 
impact on local workers is actually going to help the manager and the organization to make a decision on how to execute the recruitment strategy and how to effectively carry the organizational goals to success and analyze the behavior of the worker towards the other workers and to the work itself. All the points that have been discussed are important to make and plan a decision that will help the organization or company to understand the importance of recruiting an international workforce and its effects whether positive or negative towards the local workforce. Looking to the future the way managers recruit employees whether local or international workers, employees or top management level, will have to be planned and analyzed before making any decisions on recruitment process.

\section{References}

[1] Hawthorne, L. (2007) Labour Market Outcomes for Migrant Professionals: Canada and Australia Compared. Citizenship and Immigration Canada, Ottawa.

[2] Cynthia, D.C. and Ramesh, K.M.H.M. (2012) Working Knowledge. International Journal of Academic Research in Business and Social Sciences, 2, 530. http://hbswk.hbs.edu/item/3827.html

[3] Daniel, A. (2006) Managing Globalization. The New York Times. Harvard Business School, The New Global Business Manager, Harvard. http://www.nytimes.com/2006/02/07/business/worldbusiness/07iht-glob08.html?_r=2\&

[4] Becker, R. and Kolster, R. (2012) International Student Recruitment: Policies and Development in Selected Countries. http://www.nuffic.nl/internationalorganizations/docs/niem/documents/international-student-recruitment.pdf

[5] Charles, R. (2012) The Impact of Employment of Foreign Workers: Local Employability and Trade Union Roles in Malaysia. International Journal of Academic Research in Business and Social Sciences, 2, 531.

[6] Rousseau and McLean, P. (2008) The Contracts of Individuals and Organizations. In: Cummings, L.L. and Staw, B.M., Eds., Research in Organizational Behavior, JAI Press, Greenwich, 1-43.

[7] Youngdahl, W., Ramaswamy, K. and Dash, K. (2010) Service Offshoring: The Evolution of Offshore Operations. International Journal of Operations \& Production Management, 30, 798-820. http://dx.doi.org/10.1108/01443571011068171

[8] Anderson, N.R., de Dreu, C.K.W. and Nijstad, B.A. (2004) The Routinization of Innovation Research: A Constructively Critical Review of the State-of-the-Science. Journal of Organizational Behavior, 25, 147-174. http://dx.doi.org/10.1002/job.236

[9] Hugo, G., Rudd, D. and Harris, K. (2003) Australia’s Diaspora: It’s Size, Nature and Policy Implications. CEDA Information Paper No. 80. CEDA, Melbourne.

[10] Sebastian, S. (2007) University of California San Diego, Survey Data: Regularization Programs for Undocumented Migrants. Migration Letters, 4, 65-76.

[11] Jurgens, J. (2010) The Legacies of Labor Recruitment: The Guest Worker and Greencard Programs in the Federal Republic of Germany. Policy and Society, 29, 345-355. http://dx.doi.org/10.1016/j.polsoc.2010.09.010

[12] Keen Christine, D. (1994) Tips for Effective Strategic Planning. HR Magazine (August). 84-87.

[13] Carol, S. (1994) Journal of Organizational Change Management, 7, 45-52.

[14] Ployhart, R.E. (2006) Staffing in the 21st Century: New Challenges and Strategic Opportunities. Journal of Management, 32, 868-897. http://dx.doi.org/10.1177/0149206306293625

[15] Kang, Q.Z. (2010) Conference Board of Canada, 2011. CEO Challenge 2011. http://www.conferenceboard.ca/e-library/abstract.aspx?did=4150

[16] Peri, G. (2009) The Impact of Immigrants in Recession and Economic Expansion, Migration Policy Institute. Population Division of the Department of Economic and Social Affairs of the United Nations Secretariat, 2005. Trends in Total Migrant Stock: The 2005 Revision. http://esa.un.org/migration

[17] Harden, B. (2009) In a Shift, Japan Seeks to Help Laid-Off Immigrants Stay in the Country. Washington Post. http://www.washingtonpost.com/wpdyn/content/article/2009/01/22/AR2009012204150.html

[18] Chiswick, B.R. (2011) Immigration: High Skilled vs Low Skilled Labor?” IZA Policy Paper (28). http://ftp.iza.org/pp28.pdf

[19] Head and Ries (2004) The Quest for Foreign Skills, International Recruitment Strategies in the Asia-Pacific Region.

[20] Chiquiar, D. and Hanson, G.H. (2005) International Migration, Self-Selection, and the Distribution of Wages: Evidence from Mexico and the United States. Journal of Political Economy, 113, 239-281.

http://dx.doi.org/10.1086/427464 
[21] Clemens, M.A. and McKenzie, D. (2009) Think Again: Brain Drain. Foreign Policy. http://www.foreignpolicy.com/articles/2005/07/01/think_again_homeland_security

[22] Mark, C. (2011) Australia Department of Immigration and Citizenship (ADIC), 2012a. Trends in Migration: Australia 2010-2011. http://www.immi.gov.au/media/publications/statistics/trends-in-migration/trends-in-migration-2010-11.pdf

[23] Wadhwa, V., et al. (2011) The Grass Is Indeed Greener in India and China for Returnee Entrepreneurs. Ewing Marion Kauffman Foundation.

http://www.kauffman.org/uploadedfiles/grass-is-greener-for-returnee-entrepreneurs.pdf

[24] Karen, A.S. (2013) Immigration Bureau of Japan (IBJ). 2011. Immigration Control Report 2011. http://www.moj.go.jp/nyuukokukanri/kouhou/nyuukokukanri06_00018.html

[25] Lowell, B.L., et al. (2007) Foreign Students Coming to America: The Impact of Policy, Procedures and Economic Competition. Institute for the Study of International Migration.

[26] Farr, F. and Ford, C. (1990) Individual Innovation. In: West, M.A. and Farr, J.L., Eds., Innovation and Creativity at Work: Psychological and Organisational Strategies, Wiley, Chichester. 